\title{
STOPPED DEVELOPMENT IN OVERCROWDED CULTURES OF DROSOPHILA MELANOGASTER
}

\author{
J. L. MÉNSUA AND A. MOYA \\ Departamento de Genética, Universidad de Valencia, Dr. Moliner, 50 Burjasot \\ (Valencia), Spain.
}

Received 6.xi.82

\section{INTRODUCTION}

It has been well established in competition studies among larvae that the developmental time from larva to adult is a function, among others, of culture density (Barker and Podger, 1970). The studies on minimal food requirements show the existence of a "critical period" necessary to attain the pupal stage (Bakker, 1959, 1969; Robertson, 1963, 1964). The phenomena of competition among pre-adults are interpreted as a result of species interactions and/or genetic interactions, in the light of the methodology applied up to now (De Witt, 1960; Huang et al., 1971; Tošić and Ayala, 1981; Mather and Caligari, 1981). Generally no approach has been made to the dynamics of the larval competition process. By means of a new experimental method designated here as "overfeeding", it has been possible to analyse the dynamics of this process and to show the existence of "stopped development" in 3rd instar larvae. This phenomenon can lead to either larval death or pupation in the presence of a food supply.

\section{MATERIALS AND METHODS}

The experiment was designed in order to analyse what happens in competition cultures, and basically consists of a break in the competition conditions. The stocks used were the following: the wild type strain of Drosophila melanogaster Oregon-R (Or/Or), a wild type strain $(+/+)$ isofemale line from a cellar in Requena (Valencia, Spain) and an isofemale line carrying the cardinal (cd/cd) eye colour mutation (3-75.7) coming from the cellar previously mentioned. All experiments were carried out in a room at $25 \pm 1^{\circ} \mathrm{C}$ with $60 \pm 5$ per cent relative humidity and constant lighting.

Seventy larvae aged $2 \pm 2$ hours were placed in two kinds of vials: large vials $(10 \times 2.7 \mathrm{~cm})$ containing $5.0 \mathrm{ml}$ of Lewis medium and small vials $(4 \times 0.8 \mathrm{~cm})$ with $0.5 \mathrm{ml}$ of the same medium. A total of eight replicae was made. Each one consists of one large vial and nine small vials. The large vial was considered as control in non-competitive conditions. One small vial was not overfed and was considered as a control in highly competitive conditions. The other eight small vials were overfed as follows: each was transferred to a large vial with inclined medium (overfeeding vial) on eight different occasions. The first small vial was introduced into the overfeeding vial on the 4th day of culture, the second one two days later and so on until 18th day when the last small vial was overfeeding. After 24 hours contact between the two vials was interrupted by taking away the small vial. All larvae migrated spontaneously and rapidly to the overfeeding vial 
J. L. MÉNSUA AND A. MOYA

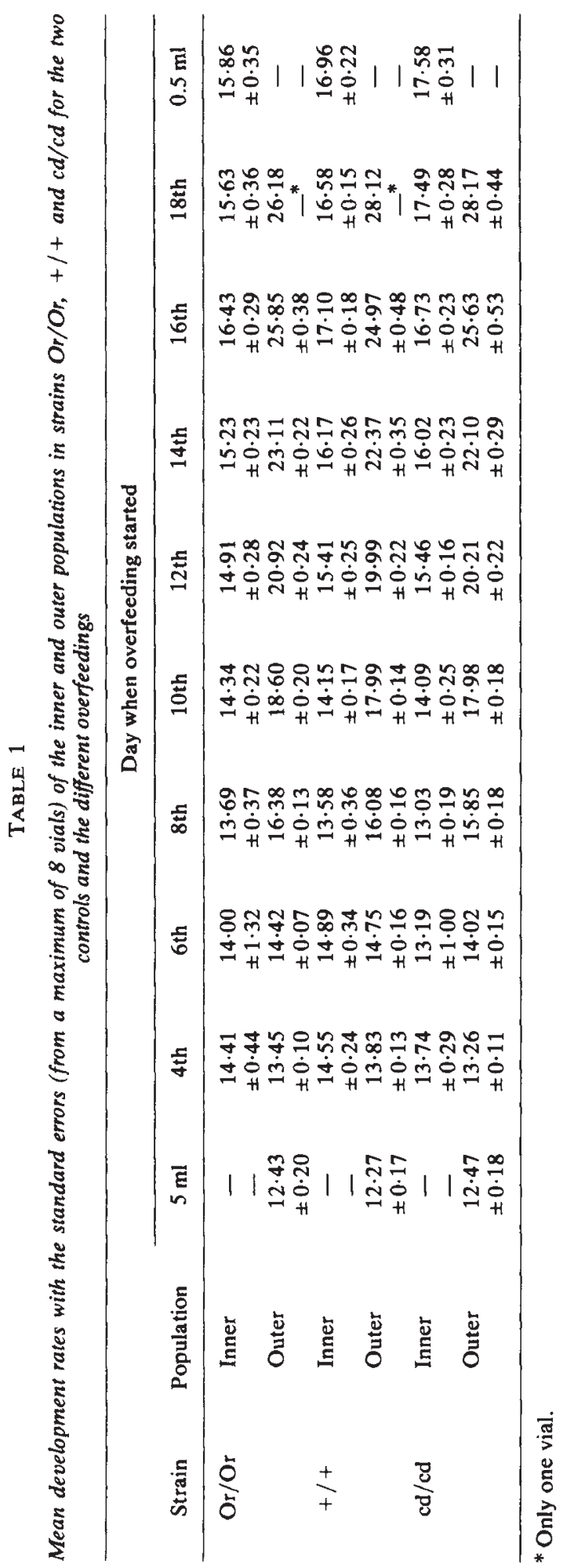


except a very few which stayed in the small vial when the overfeeding was carried out on the 4th and the 6th days of culture. In this way the larvae were separated into two groups: the inner population, composed of those larvae near pupation and pupae at the moment of overfeeding, and the outer population, composed of those larvae which had migrated to the overfeeding vial. Emerging adults were counted and removed every day up to the end of the cultures.

\section{REsUlts AND DISCUSSION}

Table 1 represents the mean developmental rates expressed in days for the two controls $(5.0 \mathrm{ml}$ and $0.5 \mathrm{ml})$, and for the inner and outer populations in the various overfeeding days. Fig. 1 represents the mean developmental

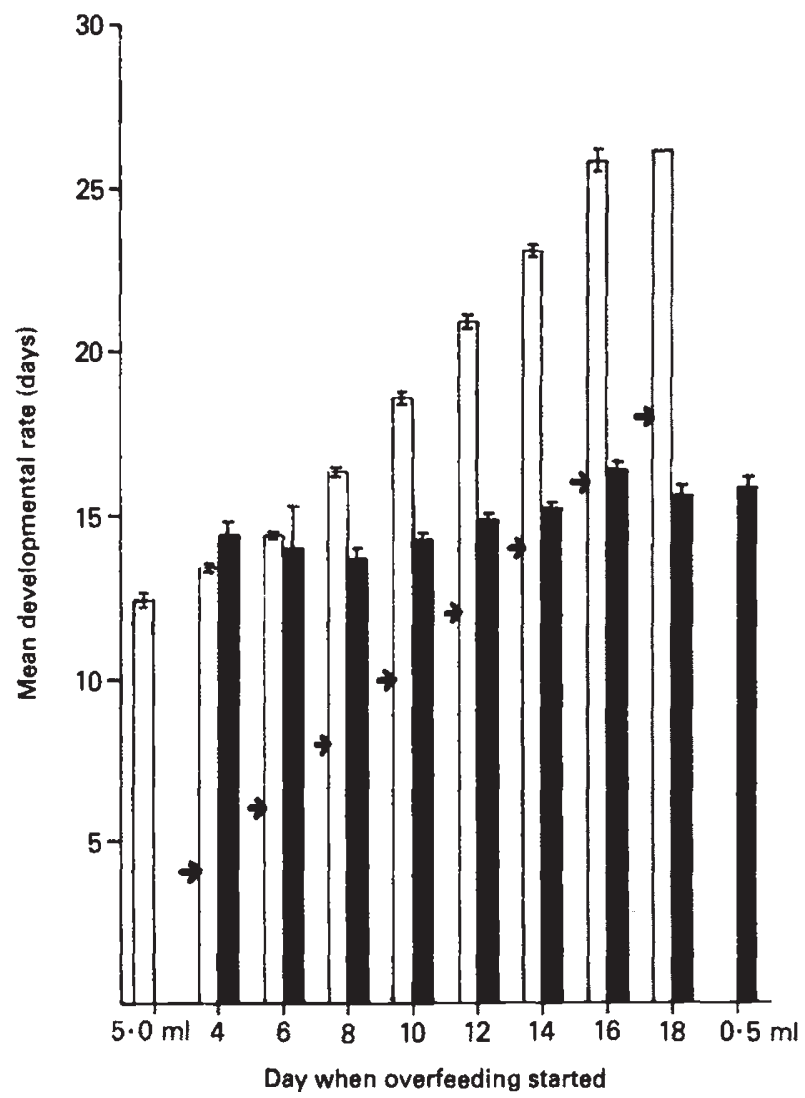

Frg 1. Histograms of mean developmental rate \pm s.e. (error bars), in days, in Oregon-R strain

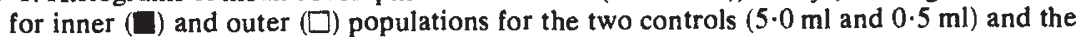
eight overfeedings. The arrows show the moment (in days) of the overfeedings.

rates of Oregon- $R$ strain. Table 2 is the summary of an ANOVA completed with regression (Bancroft, 1964; Sokal and Rohlf, 1969). It can be seen that the rate of development increases slowly in the inner population, but that in the outer population the increase is proportional to the moment of 


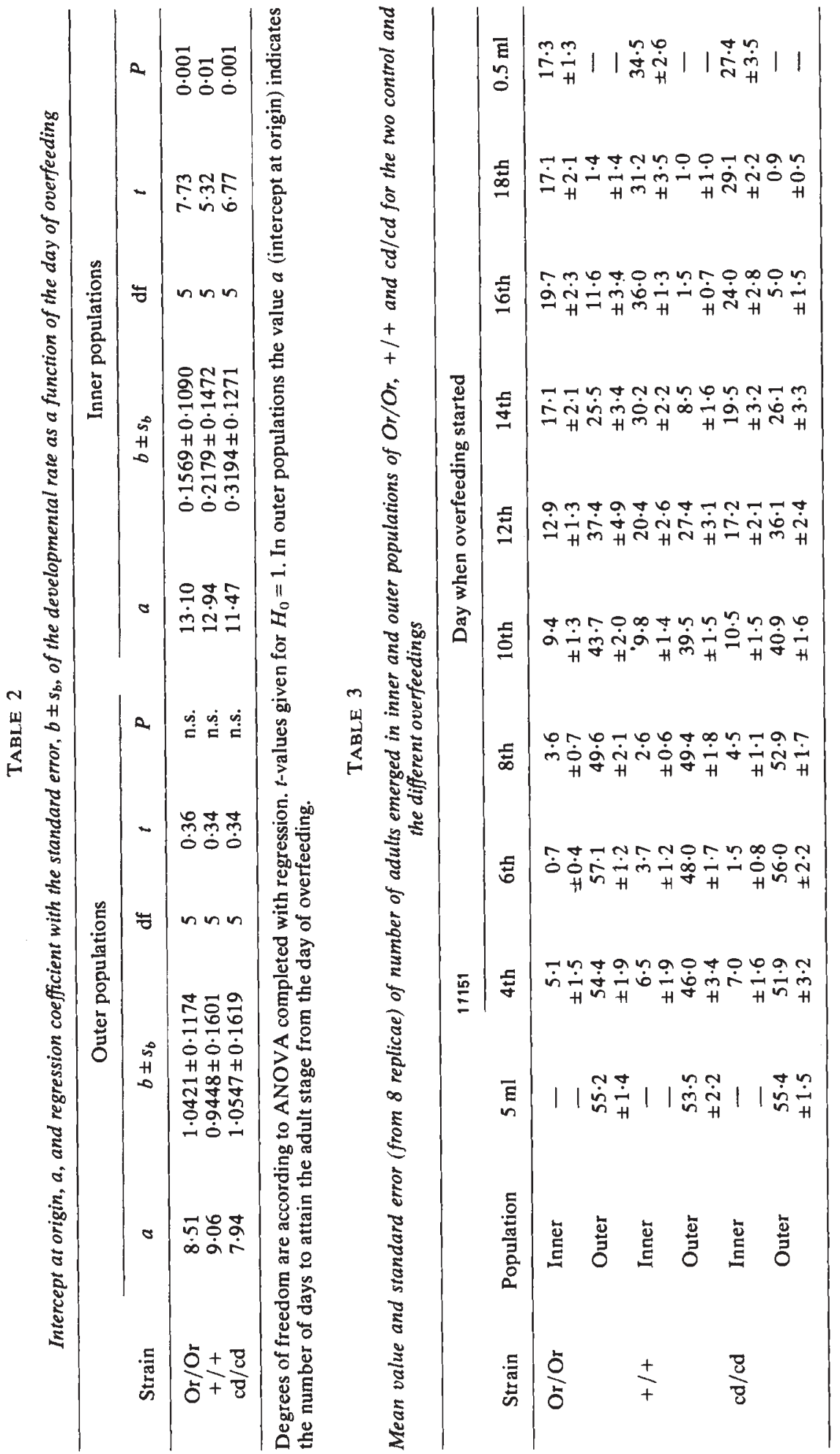


overfeeding. It seems clear from our data that the larvae collected by the overfeeding technique were all in the state called here "larval stop". The jaw analysis revealed that the stopped larvae are all in the 3rd instar. As can be seen from fig. 1 and table 2, the larvae take eight to nine days from the day of overfeeding to attain the adult stage. We have not detected any bimodality as regards larval size before the different overfeedings. The adults from the outer population were of quasi normal size. On the contrary the adults from the inner population decrease gradually in size from a normal size in the 4 th overfeeding to a minimal size in the 18 th overfeeding.

Table 3 shows the mean number of adults emerging from cultures. The individuals collected in the outer population (overfeeding vials) are the larvae stopped in the small vials before overfeeding. This fraction drops until it reaches the production level corresponding to the control culture of $0.5 \mathrm{ml}$ (high-competition). The individuals collected within the small vials are the larvae which had begun pupation before overfeeding. This last fraction rises until it reaches the level corresponding to the control culture of $0.5 \mathrm{ml}$.

The results presented here are compatible with the following conclusions.

(1) Larvae stop once the 3 rd instar has been reached. In the last overfeeding they can spend a minimum of 340 hours in this instar, whereas the 3 rd instar is 42 hours long at $25^{\circ} \mathrm{C}$ under normal conditions. This has not been found before due mainly to the experimental techniques used. Robertson (1963) analyses in each individual the minimum period that a larva has to spend in feeding in order to pupate. He found a "critical period" at the beginning of the 3 rd instar after which there is an increasing probability of pupation. Our experiment is inverse and complementary to Robertson's experience. Firstly, the analysis is at population level, not individual; secondly, the methodology consist of overfeeding instead of removing food. (2) At every overfeeding there will be a fraction of the outer population which will continue "stopped" in the larval stage from the previous overfeeding, although this fraction will be reduced each time. This is partly due to mortality, which rises with time, but also to pupation, which also rises with time. The causes of this strategy remain unknown at individual level. However, genetical variability and genotype-environment interactions, especially in relation to larval excretion products (Huang et al., 1971), might be implied.

As compared with other methodologies which analyse competition phenomena (De Witt, 1960; Huang et al., 1971; Tošić and Ayala, 1981; Mather and Caligari, 1981), this method permits one to analyse larval development precisely in competitive conditions.

In nature, situations of competition for food could cause larval stop. This point could be involved in the maintenance of insect populations in temperate regions subject to seasonal changes. A fraction of the total population could stop its development during a period as a function of the ambient temperature (inversely correlated with the rate of development (Ashburner and Thompson, 1978)) and food sources. The probability of survival of the stopped larvae would depend on the food supply. 


\section{REFERENCES}

ASHBURNER, M. AND THOMPSON, J. N. 1978. The laboratory culture of Drosophila. In Ashburner, M. and Wright T. R. F. Wright (eds.) The Genetics and Biology of Drosophila, vol. 2a, Academic Press, New York.

BAKKER, K. 1959. Feeding period, growth and pupation in larvae of Drosophila melanogaster. Entomologia exp. appl., 2, 171-186.

BAKKER, K. 1969. Selection for rate of growth and its influence on competitive ability of larvae of Drosophila melanogaster. Nether. Jour. Zool., 19, 541-595.

BANCROFT, T. A. 1964. Analysis and inference for incompletely specified models involving the use of preliminary test(s) of significance. Biometrics, 20, 427-442.

BARKER, J. S. F. AND PODGER, R. N. 1970. Interspecific competition between Drosophila melanogaster and Drosophila simulans: effects of larval density on viability, developmental period and adult body size. Ecology, 51, 170-189.

DE WITT, C. T. 1960. On competition. Versl. Landbouwk. Onderz. 66, 8-82.

HUANG, S. L., SINGH, M. AND KOJIMA, K. 1971. A study of frequency-dependent selection observed in the esterase- 6 locus of Drosophila melanogaster using a conditioned media method. Genetics, 68, 97-104.

MATHER, K AND CALIGaRI, P. D. S. 1981. Competitive interactions in Drosophila melanogaster. II. Measurement of competition. Heredity, 46, 239-244.

ROBERTSON, F. V. 1963. The ecological genetics of growth in Drosophila. 6. The genetic correlation between the duration of the larval period and body size in relation to larval diet. Genet. Res., 4, 74-92.

ROBERTSON, F. V. 1964. The ecological genetics of growth in Drosophila. 7. The role of canalization in the stability of growth relations. Genet. Res., 5, 107-126.

SOKAL, R. R. AND ROHLF, F. J. 1969. Biometry. W. H. Freeman and Company. San Francisco.

TOŠIĆ, M. AND AYALA, F. J. 1981. Density- and frequency-dependent selection at the Mdh-2 locus in Drosophila pseudoobscura. Genetics, 97, 697-701. 